\title{
Mathematics Modelling and Performance Analysis of the Heat Transfer on Vacuum Tube Collector of Water Heater Application
}

\author{
Lia Hamanda* and Gunawan Nugroho \\ Physic Engineering, Department of Engineering Physic, Institut Teknologi Sepuluh Nopember, \\ Jl. Teknik Kimia, Sukolilo Surabaya 60117, Indonesia
}

\begin{abstract}
The aim of this work is to study a mathematical modelling and simulation for predicting the thermal performance heat-pipe evacuated a solar collector for water heater, which was considered the temperature distribution along the tube axis and radius. This model used to help in studying the dynamic behaviour of the system design and the effect of influential parameter on the water heater process. The result showed that water heating is affected by the surface of collector, metrological conditions such as solar radiation and outdoor temperature, even the thermal performance of the collector.
\end{abstract}

Keywords: Heat-pipe solar collector, solar collector, solar water heater

\section{Introduction}

Solar energy consists of two types of energy, namely photovoltaic solar energy (produces electricity) and thermal solar energy (produces heat), even though solar energy is free to obtain, there are some challenges in getting and storing solar energy effectively because it is only available on daytime so the energy must be collected efficiently in order to be stored when it has been used during the day [1]. Solar collector is a tool that can be used to collect or focus the radiation of the solar. This tool is mainly used as a heater and it is possible to be used as a water heater to a personal consumption. Different collector configuration has different range of temperature, for instance, the operational temperature range of flat plate collector is between $20^{\circ} \mathrm{C}$ to $80{ }^{\circ} \mathrm{C}$ while the operational temperature range of vacuum tube collector is between $50{ }^{\circ} \mathrm{C}$ to $200{ }^{\circ} \mathrm{C}$ [2].

The most common used solar collector is actually a flat plate collector because of its low maintenance costs and simple design, however, this collector has two main weaknesses in which it losses heat due to the convection process through the glass cover layer of the collector plate and the absence of sun tracking, while vacuum tube collector has lower manufacturing cost and it convection heat loss is lower than flat plate collector [3]. On the other hand, vacuum tube collector can solve the two main weaknesses possessed by flat plate collector because vacuum tube collector has better heat insulation in comparison to the flat plate collector, due to the matter, this research was conducted with study approach and modelling simulation on a single vacuum tube collector.

\footnotetext{
* Corresponding author: liahmnd@gmail.com
} 


\section{Evacuated tube solar collector}

Solar collector is a device that used to collect and focusing solar radiation. This device mainly used as water heater and probably used as water heater for personal purposes. This collector usually placed in the rooftop. The using of solar collector giving an alternative in decreasing the cost of energy from time to time that usually completely used for water heating [4].

Another opinion said that solar collector included as heat exchanger that used to get heat energy from solar radiation, simply solar collector collect the solar radiation and convert it as the heat energy, then transfer it to the transfer fluid along the collector. Some operational parameter that might influence the collector performance such as flow rate the transfer fluid, solar radiation, ambient temperature, inlet temperature, wind velocity, weather and climate even the dust that cover the glass of solar collector [5].

An evacuated tube solar collector is made of parallel evacuated glass pipes. Each evacuated pipe consists of two tubes, one is inner and the other is outer tube. The inner tube is coated with selective coating while the outer tube is transparent. Light rays of solar radiation pass through the transparent outer tube and are absorbed by the inner tube. Both the inner and outer tubes have minimal reflection properties. The inner tube gets heated while the sunlight passes through the outer tube and to keep the heat inside the inner tube, a vacuum is created which allows the solar radiation to go through but does not allow the heat to transfer. To create the vacuum, the two tubes are fused together on top and the existing air is pumped out. Thus, the heat stays inside the inner pipes and collects solar radiation efficiently. Therefore, an evacuated tube solar collector is the most efficient solar thermal collector [6].

There are several types of solar collectors, such as U-tube type, flat-plate type, and heat pipe type. The heat pipe evacuated tubular solar collectors have unique characteristics such as anti-freezing, rapid start-up, resistance to high pressure, and easy installation and maintenance, and many countries have paid more and more attention to them. A feature that makes heat pipes attractive for use in solar collectors are their ability to operate like a thermal diode, in that the flow of heat is in one direction only. This minimizes heat loss from the transporting fluid (e.g., water) when incident radiation is low. [7]

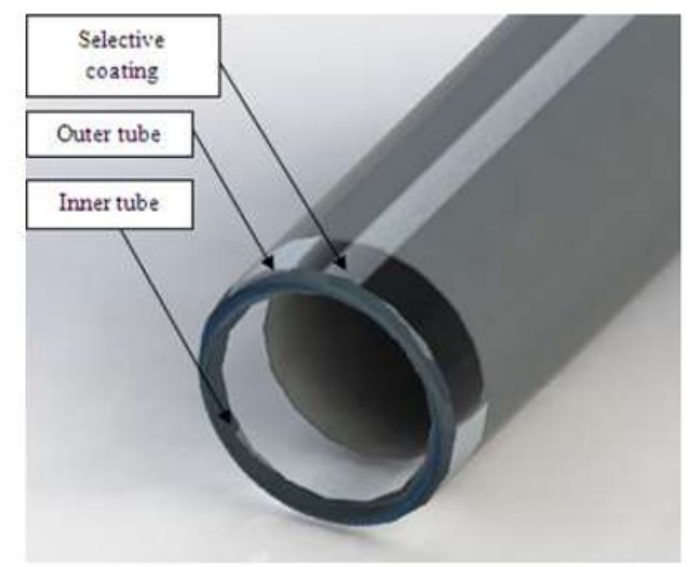

Fig. 1. Evacuated tube solar collector. 


\subsection{Thermal analysis of solar collector}

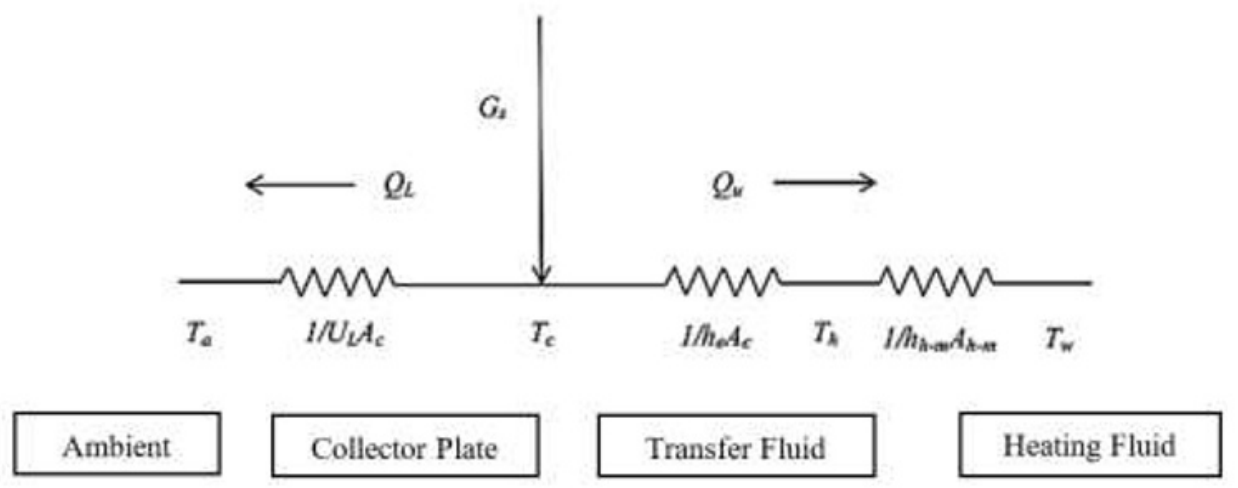

Fig. 2. Illustration of thermal network that has been simply of evacuated tube solar collector.

The prediction of solar collector needed the information on how the energy was collect by collector plate.

The solar collector performance can be assumed as:

i). Steady state condition

ii). Solar radiation that hitting the plate collector was stable

iii). Stable flow rate

iv). Constant velocity and ambient temperature.

Which assumption that have been explain, it is possible to maintain the outlet fluid temperature from collector have constant value, to determine the performance of a solar collector some basic calculations are needed to provide the information about the amount of energy absorbed and that can be utilized by the collector. Based on the first law of thermodynamic energy balance, discribe in Equation (1):

$$
\Sigma E_{\text {in }}=\Sigma E_{\text {out }}
$$

As in Equation 1 it is known that the energy used or utilized by the collector will be equal to the energy absorbed by the collector, in other words the amount of energy used to increase the temperature of the fluid will be equal to the amount of energy that can be absorbed by the solar collector. Where the energy that can be utilized in the solar collector can be calculated using the Equation (2) :

$$
Q_{u}=\dot{m} c_{p}\left(T_{o}-T_{i}\right)
$$

Whereas the energy absorbed by the solar collector is stated by Equation (3) :

$$
Q_{u}=A_{C}\left[G_{s}-U_{L}\left(T_{c}-T_{a}\right)\right]
$$

The process of heat transfer from the absorbing plate to the transfer fluid along the heat pipe can be described as follows, in Equation (4):

$$
Q_{c-h}=h_{e} A_{C}\left(T_{c}-T_{h}\right)
$$


It is assumed that $Q_{c}=Q_{c-h}$, and eleminating $T_{c}$ from Equation 3, is obtained in Equation (5) :

$$
Q_{c-h}=\frac{h_{e} / U_{L}}{h_{e} /_{U_{L}}+1} A_{C}\left[G(\tau \alpha)_{e f f}-U_{L}\left(T_{h}-T_{a}\right)\right]
$$

The heat transfer that occurs between the transfer fluid and the heated water can be described as follows, in Equation (6):

$$
Q_{h-t}=h_{h-t} A_{h-t}\left(T_{h}-T_{w}\right)
$$

Then, if it assumed that $Q_{h-t}=Q_{c-h}$ and eleminating $T_{h}$ from Equation 5 and Equation 6, the following is Equation (7) to Equation (9):

$$
\begin{gathered}
Q_{h-t}=\frac{A_{c}}{\left(U_{L} A_{c} /_{h-t} A_{h-t}\right)+\left(\frac{U_{L}}{h_{e}}+1\right)}\left[G(\tau \alpha)_{e f f}-U_{L}\left(T_{w}-T_{a}\right)\right] \\
Q_{h-t}=F_{r} A_{c}\left[G(\tau \alpha)_{e f f}-U_{L}\left(T_{w}-T_{a}\right)\right]
\end{gathered}
$$

With,

$$
F_{r}=\frac{1}{\left(U_{L} A_{c} / h_{h-m} A_{h-m}\right)+\left(\frac{U_{L}}{h_{e}}+1\right)}
$$

Evacuated tube solar collector convert the energy from solar radiation into heat energy, and collector performance usually determined from the efficiency described as the ratio of heat obtained to heat energy in sunlight which is in Equation 10:

$$
\eta=\frac{Q_{u}}{Q_{t}}=\frac{Q_{u}}{G A_{c}}
$$

So the following Equation (10) can be written as Equation (11):

$$
\eta=F_{r}(\tau \alpha)_{e f f}-F_{r} U_{L} \frac{\left(T_{w}-T_{a}\right)}{G}
$$

\section{Mathematics model}

To model a vacuum tube collector, a number of assumptions must be made, such as assuming that the insulation at the edge of the vacuum tube collector is perfect, where, there is no heat should be transferred through the working fluid to the vacuum tube collector (Conduction is neglected). In addition, the gradient of the glass layer and the absorbent plate is also assumed to be neglected. The main objective in this study lies in how to be modelling the heat transfer behaviour of the vacuum tube collector, because of that the effect of the incident angle on solar radiation is also neglected. Because the collector studied is a vacuum tube collector, the natural convection process in the vacuum tube collector is not considered.

In this paper, a gravity-assisted heat pipe has been used in the evacuated tube collector. In the steady state operation, solar irradiance heats up the outer surface of the heat pipe 
evaporator, this heat is transferred to the evaporator's inner surface by conduction, and vaporizes the heat pipe working fluid, which is considered pure water. The generated vapor flows naturally upwards by the buoyancy forces to the heat pipe condenser. The header fluid (water) absorbs the heat from the condenser as it passes over it and condenses the inside vapor. Then the condensate moves back to the evaporator by gravity and the cycle is repeated. [8]

In heat pipes the position of condenser is not restricted to any specific orientation and it may be utilized in any orientation. Gravity-assisted heat pipes are unidirectional conductors-they behave as thermal diode. If they are properly oriented, heat is transferred only from the evaporator to the condenser but never in the reverse direction. This feature can cut off the heat loss when the absorber temperature is lower than that of the liquid in the heat exchanger. Also, since heat pipes are sealed, by selecting suitable working fluids, compatible with wick and pipe materials, corrosion can be minimized. [9]

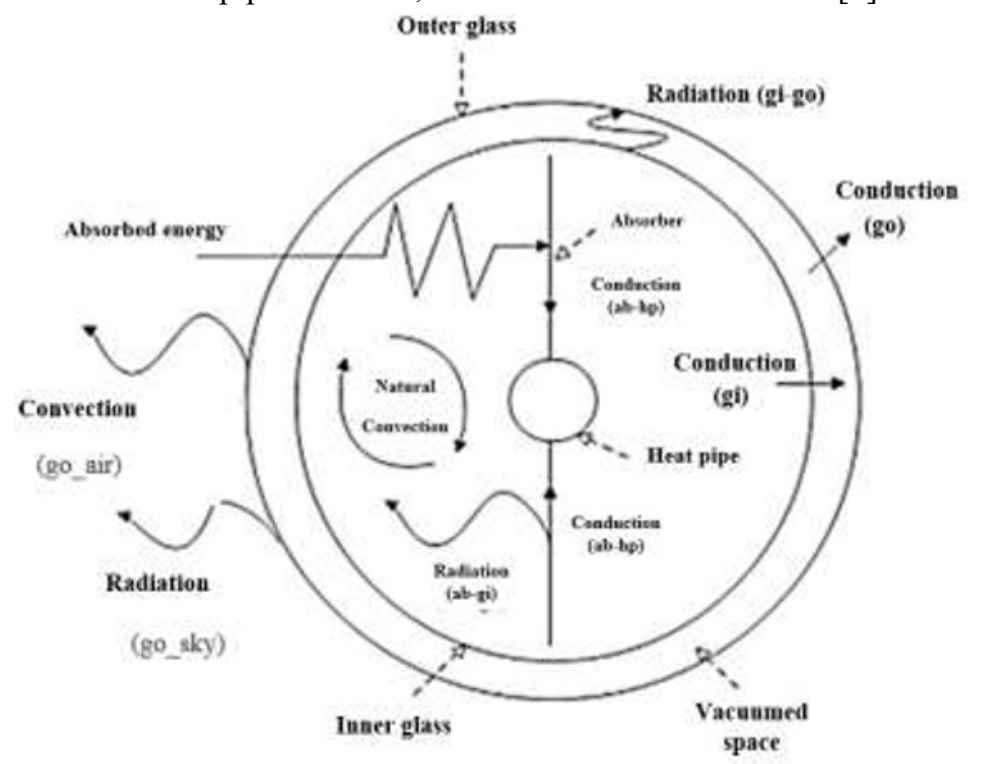

Fig. 3. Ilustration of heat transfer at evacuated tube solar collector. [10]

Where :

1. Glass cover of evacuated tube solar collector

2. Collector plate of evacuated tube solar collector

The picture above is a ilustration of heat transfer that happen in a vacuum tube collector, where each component in the collector are working fluid, absorbent plates and glass layers, then three of those component were completely analysed, because each element has a different coefficient.

Radiation and convection heat transfer occur in the vacuum tube collector cover with the ambient must be considered, in addition because it is vacuum, the heat transfer that occurs between the vacuum tube collector cover with the absorbent plate define only as radiation heat transfer.

The equation that explains the changes of temperature that occur in the vacuum tube collector cover $T_{g}$ is in Equation (11) and Equation (12)

$$
C p_{g} \delta_{g} \rho_{g} \frac{d T_{g}}{d t}=\varepsilon_{g} \sigma\left(T_{s k y}^{4}-T_{g}^{4}\right)+h_{g, a}\left(T_{a}-T_{g}\right)+\frac{\varepsilon_{c} \varepsilon_{g}}{\varepsilon_{c}+\varepsilon_{g}-\varepsilon_{c} \varepsilon_{g}} \sigma\left(T_{c}^{4}-T_{g}^{4}\right.
$$




$$
T_{\text {sky }}=p T_{a}^{1.5}
$$

Where;

$$
p=0.0552 K^{-1 / 2}
$$

The absorbent plate in the vacuum tube collector that absorbs solar radiation and transmits the heat to the fluid transfer along the vacuum tube, so the equation that explains the changes of temperature on the absorber plate in the vacuum tube collector is $T_{c}$ in Equation (13)

$$
C p_{c} \delta_{c} \rho_{c} \frac{d T_{c}}{d t}=G(\tau \alpha)+\frac{\varepsilon_{c} \varepsilon_{g}}{\varepsilon_{c}+\varepsilon_{g-} \varepsilon_{c} \varepsilon_{g}} \sigma\left(T_{g}^{4}-T_{c}^{4}\right)+h_{f, c}\left(T_{f}-T_{c}\right)
$$

In the end, the water that heated $T_{f}$ (with velocity $u$ ) that depent on time, was explain to the Equation (14) below :

$$
C p_{f} \rho_{f} \frac{\pi d_{\text {in }}^{2}}{4}\left(\frac{d T_{f}}{d t}+u \frac{d T_{f}}{d x}=\pi d_{i n} h_{f, c}\left(T_{c}-T_{f}\right)\right.
$$

\section{Result and discussion}

To determine the result of the solar collector performance, ambient temperature is one of the most important parameter on the heating process, and the distribution pattern of the transfer fluid in the solar collector The variatons in ambient temperature are shown above. This range corresponds to minimum and maximum ambient temperatures are placed in Surabaya for a years.

\begin{tabular}{|l|c|c|c|c|c|c|}
\hline \multirow{2}{*}{ Avg.temperature $\left({ }^{\circ} \mathrm{C}\right)$} & January & February & March & April & May & June \\
\cline { 2 - 7 } & 26.8 & 26.8 & 27 & 27.3 & 27.3 & 26.7 \\
\hline Min.temperature $\left({ }^{\circ} \mathrm{C}\right)$ & 23.3 & 23.2 & 23.2 & 23.3 & 23 & 22.2 \\
\hline Max.temperature $\left({ }^{\circ} \mathrm{C}\right)$ & 30.4 & 30.5 & 30.8 & 31.3 & 31.5 & 31.3 \\
\hline Precipitation/Rainfall $(\mathrm{mm})$ & 317 & 280 & 255 & 174 & 108 & 69 \\
\hline \multirow{2}{*}{ Avg.temperature $\left({ }^{\circ} \mathrm{C}\right)$} & $\mathbf{J u l y}$ & August & September & October & November & December \\
\cline { 2 - 7 } & 26.2 & 26.5 & 27.2 & 28.2 & 28.3 & 27.3 \\
\hline Min.temperature $\left({ }^{\circ} \mathrm{C}\right)$ & 21.6 & 21.6 & 22.2 & 23.5 & 23.8 & 23.5 \\
\hline Max.temperature $\left({ }^{\circ} \mathrm{C}\right)$ & 30.8 & 31.5 & 32.2 & 32.9 & 32.8 & 31.2 \\
\hline Precipitation/Rainfall $(\mathrm{mm})$ & 38 & 13 & 17 & 41 & 125 & 242 \\
\hline
\end{tabular}

Fig. 4. Surabaya wheather by month (wheater averages) 


\subsection{Solar radiation intensity variation}

The amount of the mountly average daily radiation on the solar collector, it is represented the average daily radiation of August, so the solar data of day of August has been used for the simulation of the solar collector process. The result of solar radiation are shown below:

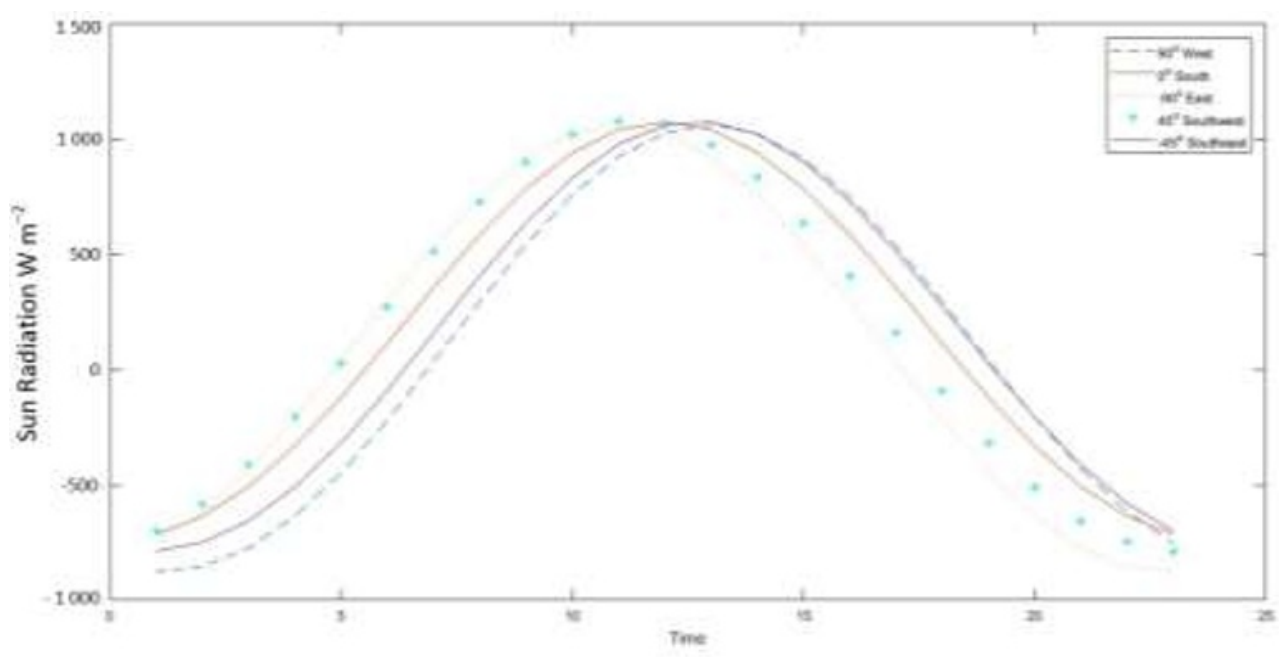

Fig. 5. Based on solar collector azimuth variation

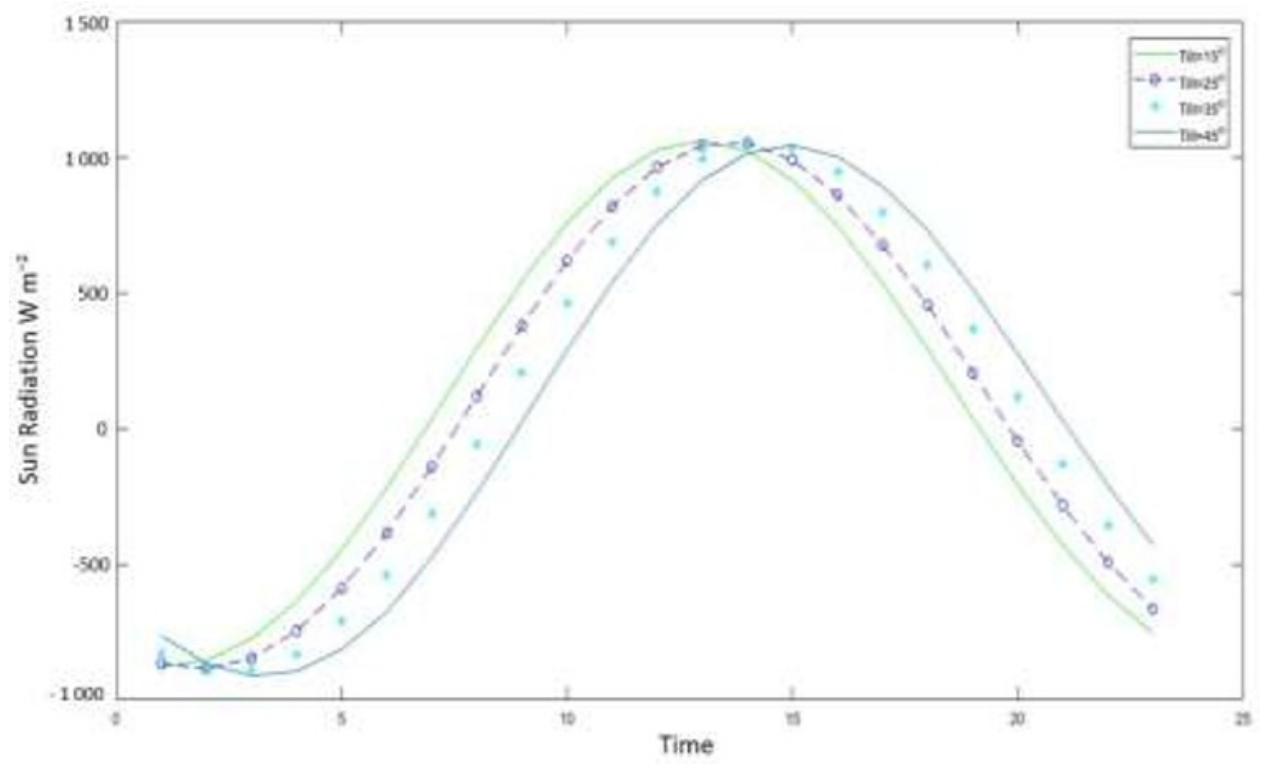

Fig. 6. Based on tilt angle solar collector variation on the total solar collector radiation 


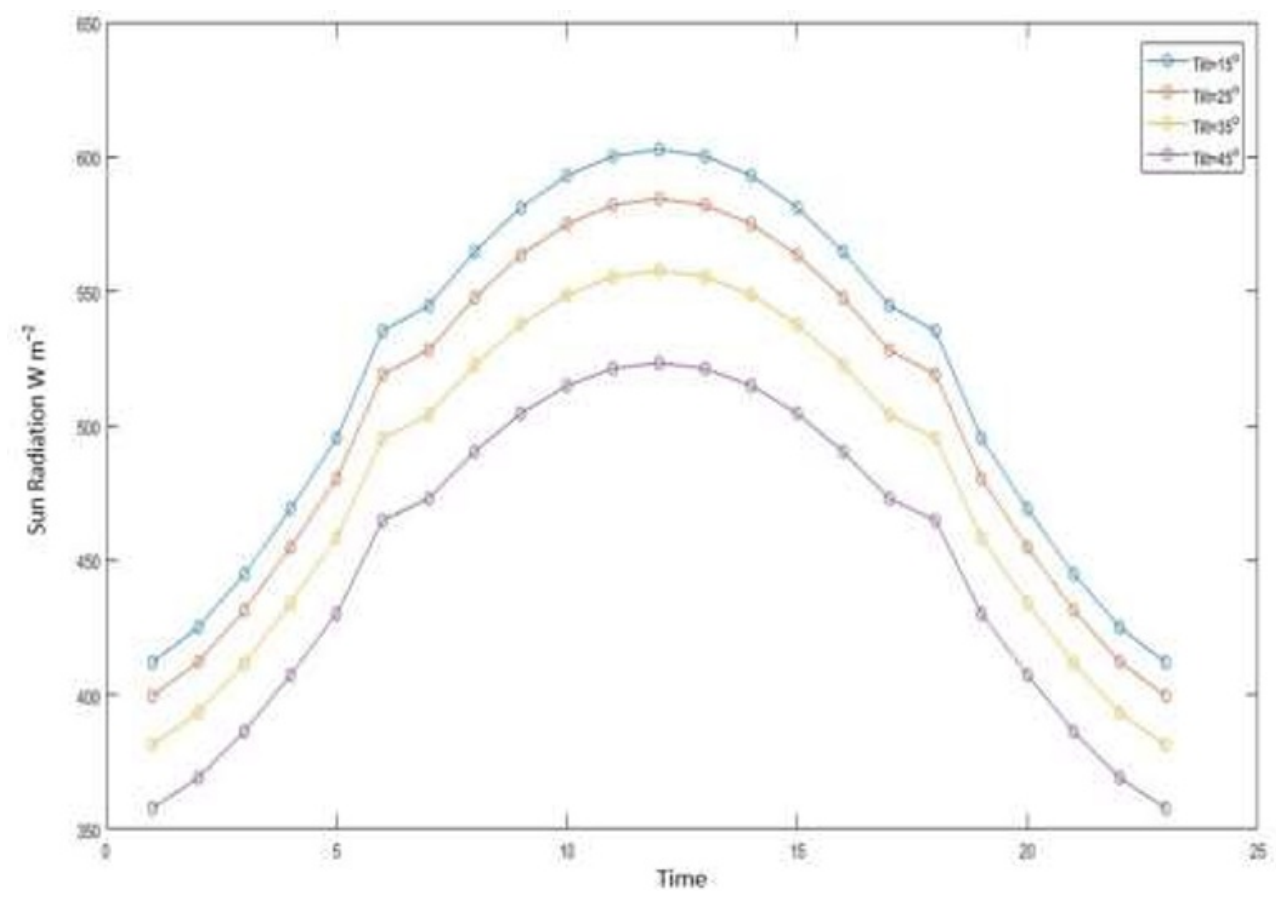

Fig. 7. Based on Influence of tilt angle variation on the diffused solar radiation

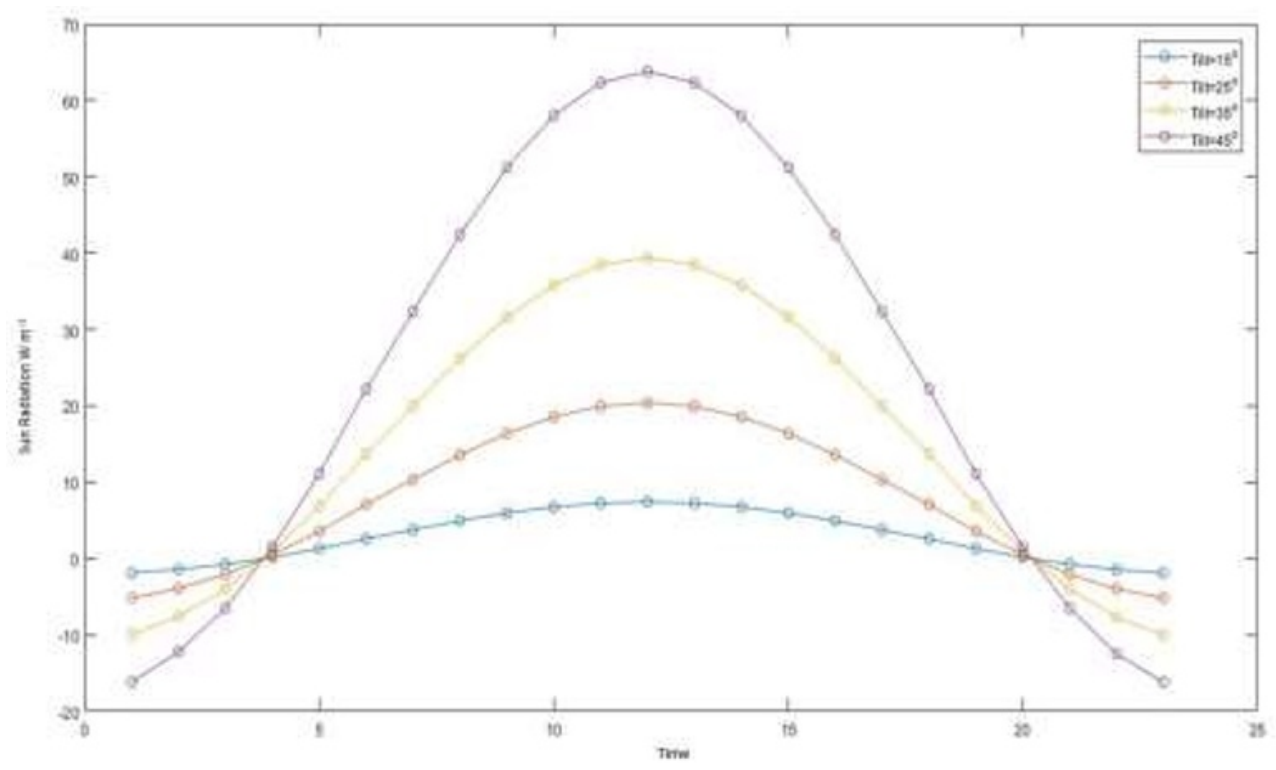

Fig. 8. Based on Influence of tilt angle variation on the reflected solar radiation 
To get the result, in this paper three approaches have been proposed for the system under the same operating conditions. In each one of these approaches, a MATLAB model of the system, which consists of a collector with a unique collector dimension and mass flow rate, has been built based on the governing equations of the system that have been explain above.

Table 1. General parameters for design of evacuated tube solar collector for each approach

\begin{tabular}{|c|c|c|c|}
\hline Collector Parameter & 1st app & 2nd app & 3rd app \\
\hline Surface area $\left(\mathrm{m}^{2}\right)$ & 2 & 4 & 8 \\
\hline Thickness $(\mathrm{m})$ & 0.05 & 0.1 & 0.125 \\
\hline Number of tubes & 8 & 12 & 16 \\
\hline Mass flow rate $\left(\mathrm{kg} \mathrm{s}^{-1}\right)$ & 0.006 & 0.015 & 0.026 \\
\hline
\end{tabular}

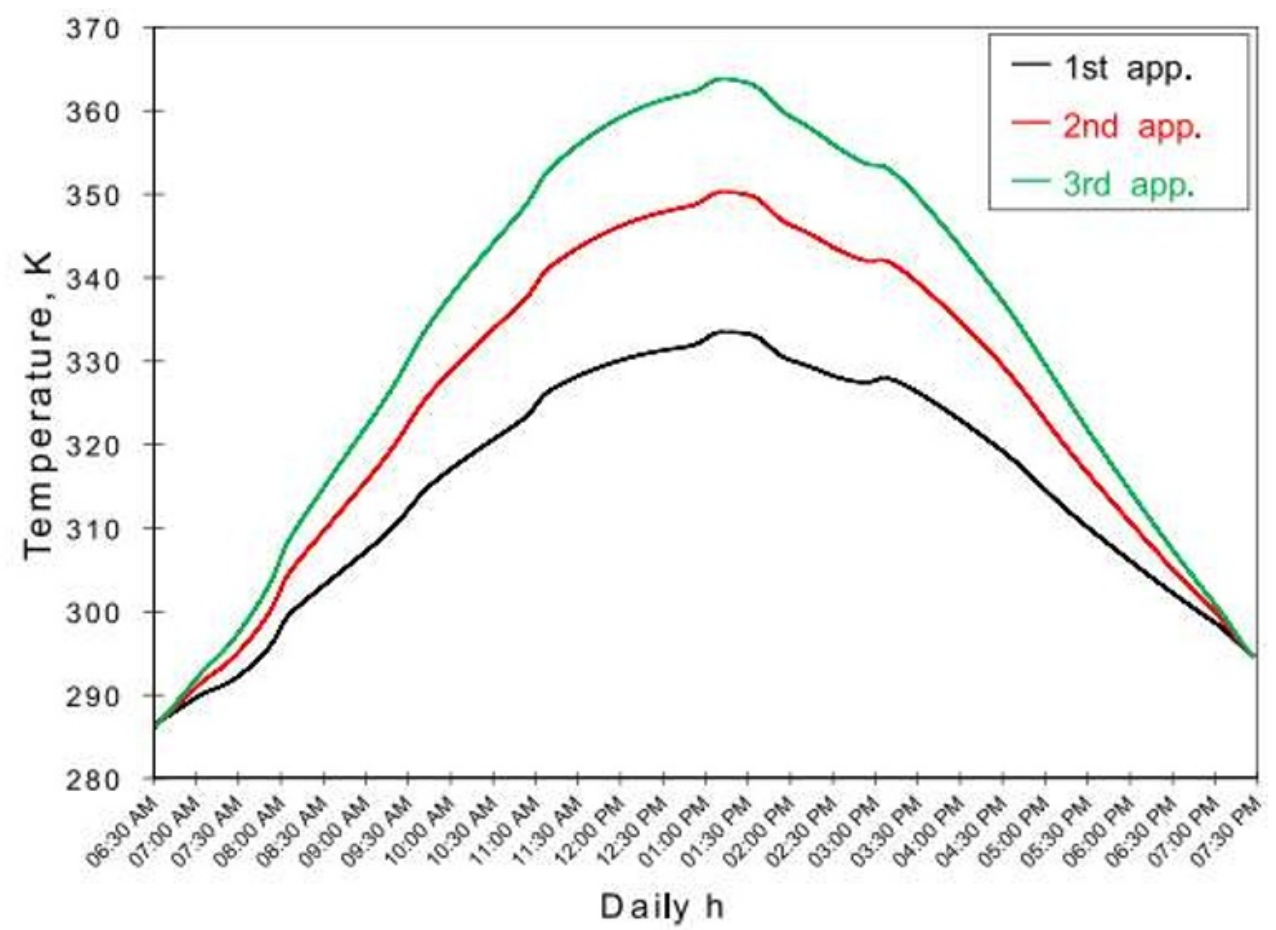

Fig. 9. The change of temperature related to the colector outlet for the te approaches 


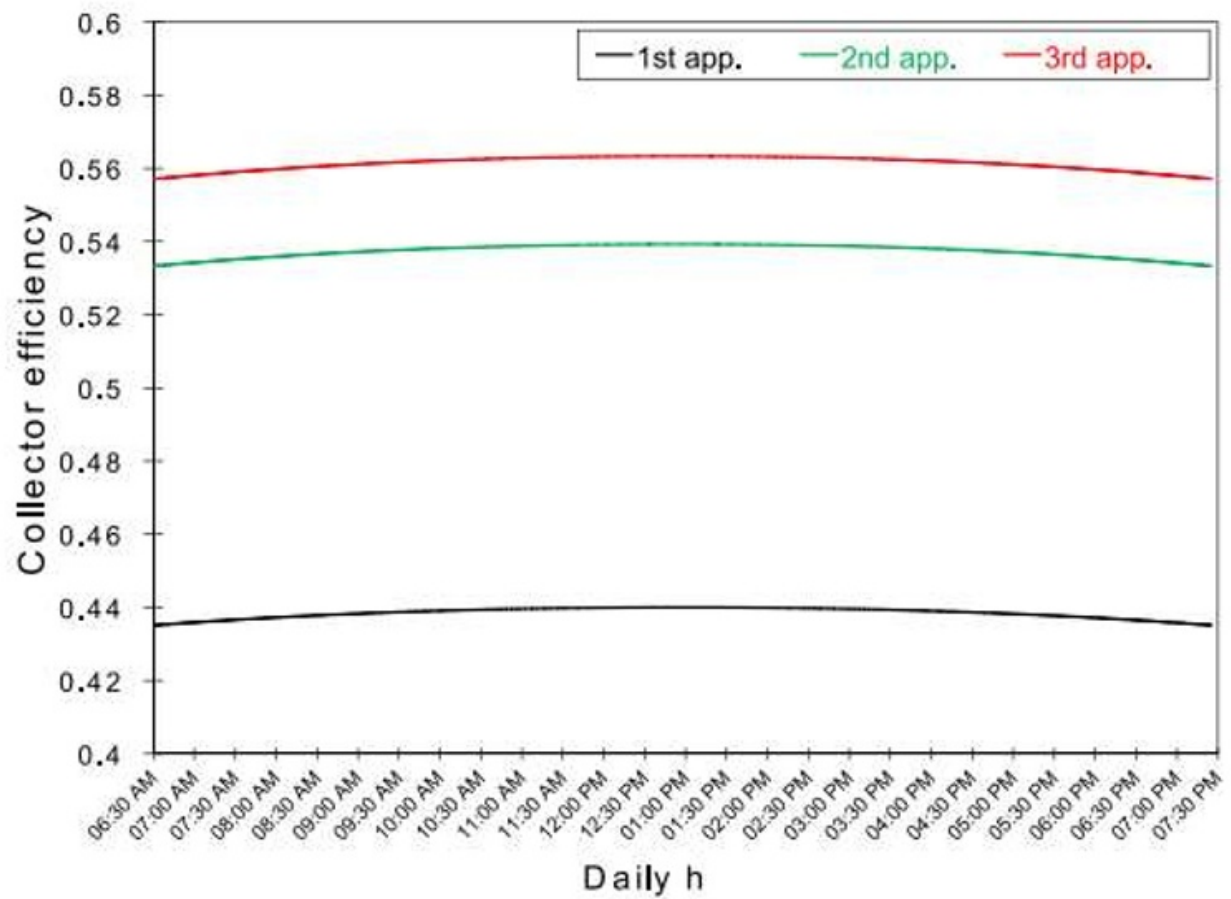

Fig. 10. The collector efficiency for the three approaches

\section{Conclusion}

In this paper, mathematical models and solutions consider the thermal performance of evacuated tube solar collector are explained. This state on the effect of parameters on the thermal efficiency of evacuated tube solar collector are shown: i) The thermal efficiency of the evacuated tube solar collector clearly will not increase along the increasing the length of the collector. ii) Optimal design to get the higher thernal efficiency is necessary for the evacuated tube solar collector and the mainly parameters to get the optimal design value is the local meteorogical solar irradiance conditions. iii) The thermal efficiency of the solar collector with the high heat loss coefficient has the poorer thermal performance when it is applied in a cold meteorogical conditions.

\section{References}

1. Morrison, G. L., Budihardjo, I., \& Behnia, M. Solar Energy.,78:257-267. (2005). https://www.sciencedirect.com/science/article/abs/pii/S0038092X0400249X

2. M.A. Sabiha, R. Saidur, S. Mekhilef, O. Mahian, Renew. Sust. Energ. Rev., 51:1038-1054(2015). https://www.sciencedirect.com/science/article/pii/S1364032115006632

3. A. Sha, M. Khiadani, A. Nosrati, Renew. Sust. Energ. Rev., 95:273-304 (2018). https://www.sciencedirect.com/science/article/pii/S1364032118305239

4. Vettrivel, H., \& Mathiazhagan, P. Comparison Study of Solar Flat Plate Collector with Single and Double Glazing Systems. 7, 1-9 (2017). https://www.ijrer.org/ijrer/index.php/ijrer/article/view/5397/pdf 
5. W. Bandara, B. Amarasekara, C. Rupasinghe, Procedia Eng., 212:1295-1302 (2017). https://www.sciencedirect.com/science/article/pii/S1877705818301930

6. M.A. Sabiha, R. Saidur, S. Mekhilef, O. Mahian, Renew. Sust. Energ. Rev., 51:1038-1054(2015).

https://www.sciencedirect.com/science/article/pii/S1364032115006632

7. Y. Tong, H.M. Kim, H.H. Cho, JMST, 30(2):903-913(2016). https://link.springer.com/article/10.1007/s12206-016-0144-3

8. M.B. Elsheniti, A. Kotb, O. Elsamni, Appl. Therm. Eng., 154:315-325(2019). https://www.sciencedirect.com/science/article/abs/pii/S135943111836040X

9. E. Azad, Exp. Therm. Fluid. Sci., 32(8):1666-1672(2008). https://www.sciencedirect.com/science/article/pii/S0894177708000733

10. A. Shafieian, M. Khiadani, A. Nosrati, Solar Energy, 193:227-243(2019). https://www.sciencedirect.com/science/article/pii/S0038092X19309090 